BEZERRA, A.M.E.; MOMENTÉ, V.G.; MEDEIROS FILHO, S. Germinação de sementes e desenvolvimento de plântulas de moringa (Moringa oleifera Lam.) em função do peso da semente e do tipo de substrato. Horticultura Brasileira, Brasília, v.22, n.2, p.295-299, abril-junho 2004.

\title{
Germinação de sementes e desenvolvimento de plântulas de moringa (Moringa oleifera Lam.) em função do peso da semente e do tipo de substrato
}

\author{
Antonio Marcos E. Bezerra ${ }^{1}$; Valéria G. Momenté2 ${ }^{2}$ Sebastião Medeiros Filho ${ }^{3}$ \\ ${ }^{1}$ UFPI-CCA, Depto. Planejamento e Política Agrícola, 64049-550 Teresina-PI; E-mail: esmeraldo@ufpi.br; ${ }^{2}$ UFT, Pró-Reitoria Pesquisa e \\ Pós-Graduação, C. Postal 111, 77001-970 Palmas-TO; E-mail: valeria@uft.edu.br; ${ }^{3}$ UFC-CCA, Depto. Fitotecnia, C. Postal 12.168, \\ 60356-001 Fortaleza-CE; E-mail: filho@ufc.com.br
}

\begin{abstract}
RESUMO
Moringa oleifera Lam. é uma espécie arbórea originária do noroeste indiano, cultivada graças ao seu valor alimentar, medicinal, industrial e no tratamento de água para o consumo humano. Os efeitos do peso de sementes e do substrato na germinação e desenvolvimento das plântulas foram determinados, sob condições de casa de vegetação (sombrite 50\% com nebulização intermitente) em Fortaleza (CE), de 29/11 a 14/12/02. Os tratamentos constaram de arranjo fatorial $3 \times 3$ referente a três categorias de semente: pesadas $(272,41$ g/1000 sementes), médias (218,88 g/1000 sementes) e leves (177,07 g/1000 sementes); e três substratos: vermiculita; Plantmax ${ }^{\circledR}$ e uma mistura à base de solo esterilizado $(\mathrm{S})$, húmus de minhoca $(\mathrm{H})$ e pó de coco lavado (PC), na proporção de 2:1:1, dispostos em delineamento inteiramente casualizado com quatro repetições (24 sementes/repetição). Efetuou-se a semeadura das três classes de pesos de sementes em bandejas de isopor de 72 células contendo os substratos, avaliando-se a percentagem, velocidade e tempo médio de germinação, altura da plântula, massa seca da parte aérea e massa seca total. As sementes pesadas e médias apresentaram maior percentagem e velocidade de germinação do que as leves; as sementes pesadas proporcionaram plântulas mais vigorosas; no substrato Plantmax ${ }^{\circledR} \mathrm{e}$ na mistura $(\mathrm{S}+\mathrm{H}+\mathrm{PC})$ a percentagem e a velocidade de germinação foi superior à vermiculita; e as plântulas desenvolveram-se melhor no substrato Plantmax ${ }^{\circledR}$.
\end{abstract}

Palavras-chave: Moringa oleifera, Moringaceae, sementes, germinação, vigor.

\begin{abstract}
Germination of seeds and seedling development of drumstick as a function of seed weight and substrate type

To compensate the shortage of information on the influence of seed weight and substrate over the germination and seedling development of Moringa oleifera an experiment was conducted under greenhouse conditions (50\% of natural light with intermittent nebulization) in Fortaleza, Ceará State, Brazil. The treatments consisted of a $3 \times 3$ factorial arrangement [three seed weights: heavy (272.41 g/1000 seeds); medium (218.88 g/1000 seeds) and light (177.07 g/1000 seeds) and three substrates: vermiculite; Plantmax ${ }^{\circledR}$ and a $\mathrm{v} / \mathrm{v}$ 2:1:1 mixture based on sterilized soil (S) plus earthworm humus $(\mathrm{H})$ and washed powdered coconut peels (PCP), respectively] disposed on an entirely randomized design with four repetitions (24 seeds/repetition). The three seed classes were sown in isopor trays with 72 cells containing the respective substrate. The percentage, rate and average time for germination; height and dry weight of total and aerial parts of the seedling were measured. Heavy and medium seeds presented a higher percentage and rate of germination than light seeds; heavy seeds yielded more vigorous seedlings; the commercial substrate Plantmax ${ }^{\circledR}$ and the mixture $(\mathrm{S}+\mathrm{H}+\mathrm{PCP})$ allowed a higher percentage and germination rate than vermiculite; the seedlings showed a better development on the commercial substrate Plantmax ${ }^{\circledR}$.
\end{abstract}

Keywords: Moringaceae, Moringa oleifera, seeds; germination, vigor, substrate.

\section{(Recebido para publicação em 6 de maio de 2003 e aceito em 20 de março de 2004)}

$M^{2}$ oringa oleifera Lam. (sin.: $M$. pterygosperma Gaertn., $M$. moringa (L.) Millsp., M. nux-ben Perr., Hyperanthera moringa Willd. e Guilandina moringa Lam.) é espécie perene, da família Moringaceae, originária do noroeste indiano, amplamente distribuída na Índia, Egito, Filipinas, Ceilão, Tailândia, Malásia, Burma, Paquistão, Singapura, Jamaica e Nigéria (Ramachandran et al., 1980; Pio Corrêa, 1984). É cultivada devido ao seu valor alimentar (folhas, frutos verdes, flores e sementes torradas); forrageiro (folhas, frutos e sementes); medicinal (todas as partes da planta); condimentar (principalmente as raízes), culinário e na in- dústria de cosméticos (óleo extraído das sementes), melífero (flores); combustível (madeira e óleo) e no tratamento de água para o consumo humano (cotilédones e tegumento das sementes) (Jahn, 1989; Morton, 1991; Cáceres et al., 1991; Gassenchimidt et al., 1995; Palada, 1996; Gerdes, 1996; Gerdes 1997; Warhurst et al. 1996; Warhurst et al.1997; Makkar e Becker, 1997; Matos, 1998; Silva e Kerr, 1999; Oliveira et al., 1999).

No Brasil há um esforço no sentido de difundi-la como hortaliça rica em vitamina A (Amaya et al., 1992; Kerr et al., 1998; Silva e Kerr, 1999); pois as suas folhas, com cerca de 23.000 UI de vitamina A, sobressaem-se entre olerícolas consagradas como brócolis, cenoura, couve, espinafre e alface, que possuem, respectivamente, 5.000; $3.700 ; 2.200 ; 1.900 ; 1.000$ UI de vitamina A (Silva e Kerr, 1999). Nas zonas rurais do nordeste brasileiro a utilização das sementes de moringa no tratamento d'água para o consumo humano tem sido prática freqüente (Gerdes, 1997; O filtro..., 1999), dada a escassez de água potável para a população rural nessa região.

A moringa é uma planta alógama que se propaga por sementes e estacas. Nas condições indianas, Jahn (1989), recomenda a produção de mudas em sacos 
de polietileno, com substrato formado à base de solo preto, solo vermelho e esterco bovino curtido, na proporção de $1: 1: 1$, procedendo-se à semeadura a 1,0 $\mathrm{cm}$ de profundidade e colocando-as para germinar à meia sombra, com irrigação leve e individual todos os dias. Desta maneira, assegura a autora, as mudas estão prontas para o transplante aos três meses de idade, quando atingem $40 \mathrm{~cm}$ de altura. Bezerra et al. (1997) verificaram que a germinação de sementes de moringa, intactas e desprovidas de tegumento, em areia a $25^{\circ} \mathrm{C}$, situou-se em torno de 69 e $68 \%$, respectivamente, onde a remoção do tegumento acelerou o processo, obtendo-se resultados semelhantes também sob condições de campo. Trabalhando com a mesma espécie, Oliveira (2000) observou um tempo médio de germinação de 8,76 e 8,05 dias para sementes intactas e sem tegumento, respectivamente, sendo que sob condições de casa de vegetação (sombrite 50\% com nebulização intermitente) as plântulas desenvolveram-se melhor do que em germinador de sala a $25^{\circ} \mathrm{C}$.

Em muitas espécies o peso da semente é um indicativo de sua qualidade fisiológica, sendo que em um mesmo lote, sementes leves, normalmente, apresentam menor desempenho do que as pesadas. Nesse sentido, Martins et al. (2000) verificaram que o peso da semente do palmito-vermelho (Euterpe espirotoantensis Fernandes) influenciou a percentagem e o índice de velocidade de germinação. Os autores observaram que a relação funcional entre a percentagem de germinação final obedeceu a uma curva logística, enquanto que para o índice de velocidade de germinação a relação ajustou-se a uma equação de segundo grau. Bezerra et al. (2002b) constataram que a classificação das sementes de copaíba (Copaifera langsdorffii Desf.) por peso não afetou a percentagem, velocidade e tempo médio de germinação, porém as plântulas oriundas de sementes pesadas $(0,78 \mathrm{~g} /$ semente) foram mais vigorosas do que as demais classes $(0,55 ; 0,63$ e $0,66 \mathrm{~g} /$ semente).

O tipo de substrato pode afetar a germinação e o desenvolvimento das plântulas e a sua escolha deve ser feita em função das exigências da semente em relação ao seu tamanho e formato. As funções básicas do substrato são a sustentação da planta e o fornecimento de nutrientes, água e oxigênio (Gonçalves, 1995). Os substratos hortícolas são constituídos por vermiculita expandida, materiais orgânicos (turfa, casca de Pinus, casca de arroz carbonizada ou composto orgânico), fertilizantes e aditivos, sendo encontrados substratos prontos para o uso, formulados por firmas idôneas, disponíveis no mercado (Filgueira, 2000), como o Plantmax ${ }^{\circledR}$. Uma alternativa ao alto custo dos substratos comerciais é a utilização de matérias-primas regionais como o pó de coco (fibra de coco verde ou maduro), de fácil obtenção no Nordeste do Brasil. Segundo Carrijo et al. (2002) as boas propriedades físicas da fibra de coco, a sua não reação com os nutrientes da adubação, sua longa durabilidade sem alteração de suas características físicas, a possibilidade de esterilização, a abundância da matéria prima que é renovável e o baixo custo para o produtor, faz da fibra de coco verde um substrato dificilmente superável por outro tipo de material, mineral ou orgânico, no cultivo sem solo de hortaliças e flores. A esse respeito Silveira et al. (2002) observaram em tomate (Lycopersicon esculentum) cv. Santa Adélia, que o pó de coco, embora proporcionasse maior percentagem de germinação $(90,63 \%)$ do que o Plantmax ${ }^{\circledR}(67,18 \%)$, as mudas nele produzidas foram menos vigorosas que no substrato comercial, sendo esse problema corrigido quando o pó de coco foi misturado com Plantmax ${ }^{\circledR}$ ou húmus de minhoca. Ledo et al. (2002) observaram que a percentagem de germinação e a velocidade de emergência de sementes de pupunha (Bactris gasipaes Kunth) em areia foram superior a vermiculita. Bezerra et al. (2002a) verificaram em melão-de-São-Caetano (Momordica charantia L.) que a vermiculita reduziu a percentagem e velocidade de germinação, bem como o desenvolvimento das plântulas, quando comparada como o substrato comercial Plugmix $囚$. Face ao exposto, objetivouse neste trabalho, avaliar o efeito do peso da semente e do substrato na germinação e no desenvolvimento das plântulas de moringa.

\section{MATERIAL E MÉTODOS}

As sementes utilizadas no ensaio foram colhidas, em 18/11/2002, de plantas matrizes existentes no Horto de Plantas Medicinais da Fazenda Experimental Vale do Curu da Universidade Federal do Ceará (UFC), localizada em Pentecoste, Ceará.

Após a colheita as sementes foram acondicionadas em sacos plásticos e transportadas para o Laboratório de Análise de Sementes da UFC. Na amostra de trabalho procedeu-se a separação das sementes em três classes de pesos: pesadas (272,41 g/1000 sementes), médias $(218,88 \mathrm{~g} / 1000$ sementes $)$ e leves (177,07 g/1000 sementes). Os teores de água das três classes foram avaliados, conforme prescrevem as Regras para Análise de Sementes (Brasil, 1992), apresentando 7,6; 7,8 e 7,8\%, respectivamente.

Os tratamentos constituíram-se de um arranjo fatorial $3 \times 3$, representado pela combinação de três classes de sementes (pesadas, médias e leves) com três tipos de substrato (vermiculita; Plantmax $^{\circledR}$ e uma mistura composta de solo esterilizado $(\mathrm{S})$, húmus de minhoca (H) e pó de coco lavado (PC) na proporção (em v/v) de 2:1:1), dispostos em um delineamento inteiramente casualizado com quatro repetições (24 sementes/repetição), perfazendo 36 parcelas. A análise química da mistura $\mathrm{S}+\mathrm{H}+\mathrm{PC}$ apresentou para os macronutrientes, em g. $\mathrm{kg}^{-1}, \mathrm{~N}=0,69$; $\mathrm{P}=1,13 ; \mathrm{K}=60 ; \mathrm{Ca}=5 ; \mathrm{Mg}=3 ; \mathrm{Na}=27,4$ e $\mathrm{S}=2$, e para os micronutrientes, em mg.kg-1 ${ }^{-1} \mathrm{Cu}=42 ; \mathrm{Fe}=6.980 ; \mathrm{Mn}=93 \mathrm{e}$ $\mathrm{Zn}=30$. Os substratos foram dispostos em doze bandejas de isopor de 72 células, semeando-se uma semente por célula. Em seguida, as bandejas foram colocadas em uma casa de vegetação (sombrite 50\% com nebulização intermitente), permanecendo nesse ambiente por 15 dias.

As variáveis analisadas foram: germinação [utilizaram-se 96 sementes por tratamento divididas em quatro parcelas de 24 , procedendo-se à contagem do número de plântulas normais, de cada parcela, aos 15 dias após a semeadura, com os resultados expressos em percen- 
tagem]; índice de velocidade de germinação [realizaram-se contagens diárias das sementes germinadas durante 15 dias, adotando-se a metodologia recomendada por Maguire (1962)]; tempo médio de germinação [calculado de acordo com a fórmula proposta por Labouriau (1983), com o resultado expresso em dias]; altura da plântula [as plântulas normais de cada parcela foram medidas aos 15 dias com o auxílio de uma régua graduada em centímetros, do colo até o ponto de inserção do folíolo terminal]; e massas secas da parte aérea e total [após a retirada das plântulas normais dos substratos, procedeu-se à remoção dos cotilédones e o corte das raízes no ponto de inserção com o caule]. A parte aérea e as raízes das plântulas de cada uma das parcelas foram acondicionadas, separadamente, em sacos de papel e colocadas em estufa com circulação de ar forçado regulada a $80^{\circ} \mathrm{C}$ por 24 horas, efetuando-se as pesagens em balança digital, de três casas decimais, sendo a massa seca da parte aérea e total (parte aérea + raízes) dada pela divisão das pesagens de cada parcela pelo número de plântulas normais correspondentes, com os resultados expressos em gramas por plântula, de acordo com Nakagawa (1994).

Os dados obtidos das seis variáveis foram submetidos à análise da variância e as médias comparadas conforme Ferreira (1996), pelo teste de Tukey a $5 \%$ de probabilidade.

\section{RESULTADOS E DISCUSSÃO}

A germinação (Figura 1a) foi estatisticamente semelhante nos substratos Plantmax $\AA(99,3 \%)$ e na mistura à base de solo (S), húmus de minhoca $(\mathrm{H})$ e pó de coco (PC) (98,3\%). As sementes exibiram germinação semelhante tanto na vermiculita $(96,6 \%)$ quanto na mistura $(98,3 \%)$, entretanto, o valor da vermiculita foi diferente do valor obtido com Plantmax ${ }^{\circledR}$. A germinação das sementes de moringa no Plantmax ${ }^{\circledR}$ foi superior à germinação verificada por Silveira et al. (2002), em tomateiro, utilizando o mesmo substrato. Na mistura $(\mathrm{S}+\mathrm{H}+\mathrm{PC})$ as sementes apresentaram germinação semelhante à observada por Silveira et al. (2002), em tomate,
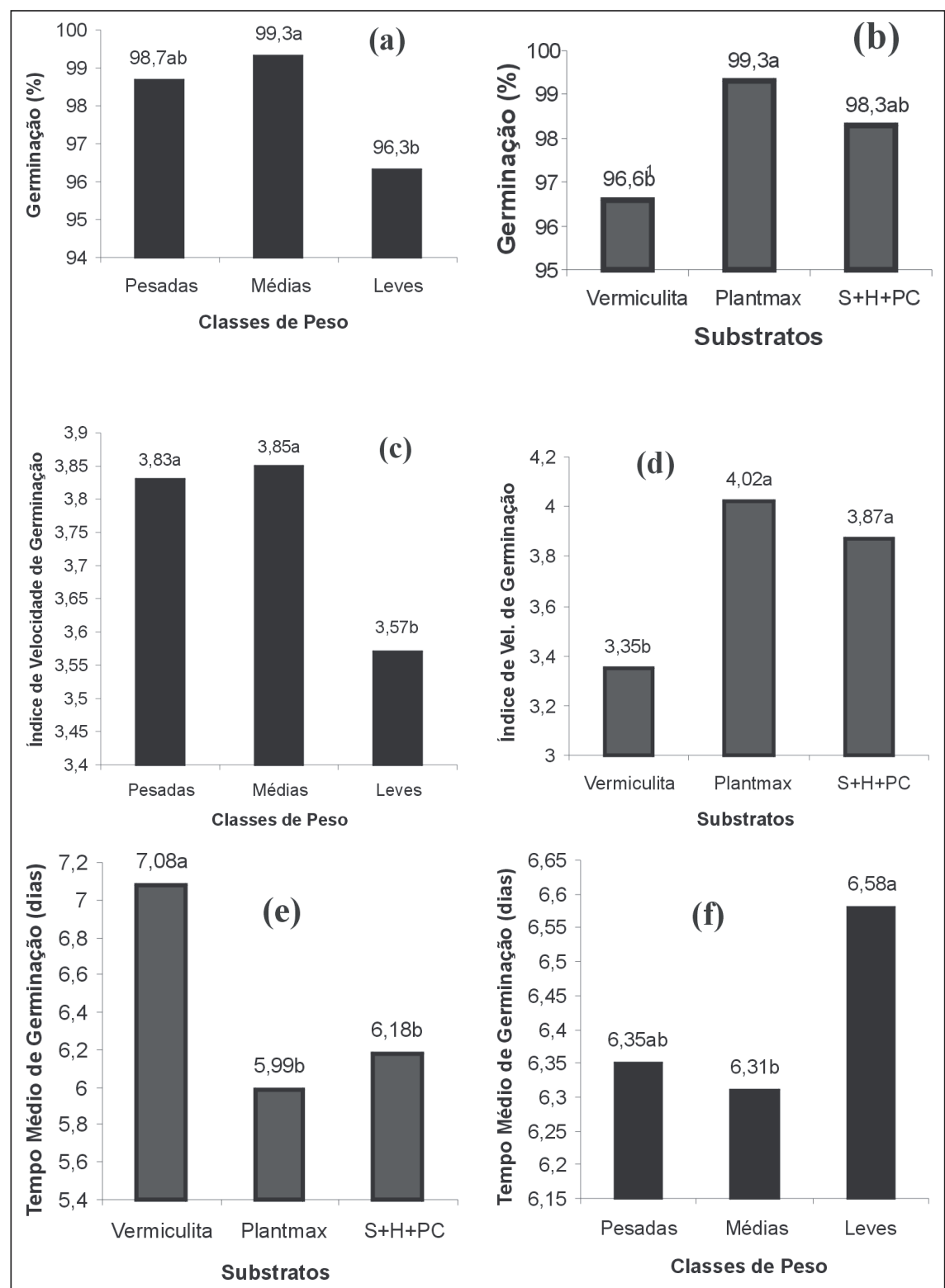

Figura 1. Percentagem (a e b), velocidade (c e d) e tempo médio de germinação (e e f) de Moringa oleifera em função do peso da semente e do tipo de substrato. Fortaleza, UFC, 2003 ${ }^{1}$ Médias seguidas da mesma letra minúscula, no topo das colunas, não diferem entre si pelo teste de Tukey, em nível de 5,0\% de probabilidade.

no substrato $\mathrm{H}+\mathrm{PC}(93,75 \%)$. A capacidade de germinação em vermiculita $(96,6 \%)$ foi muito superior à obtida por Bezerra et al. (2002a) em Momordica charantia (14\%).

A classificação das sementes por peso evidenciou que as sementes pesadas $(98,7 \%)$ e as médias $(99,3 \%)$ demonstraram o mesmo desempenho germinativo (Figura 1b), tendo as sementes leves $(96,3 \%)$, comportamento similar às pesadas. Essa pequena variação manifestada na expressão germinativa das sementes pesadas, médias e leves também foi constatada por
Bezerra et al. (2002b), em Copaifera langsdorffii Desf.

$O$ índice de velocidade de germinação na vermiculita $(3,35)$ (Figura 1c), foi estatisticamente diferente do observado no Plantmax ${ }^{\circledR}(4,02)$ e $\mathrm{S}+\mathrm{H}+\mathrm{PC}$ $(3,87)$. Comportamento semelhante foi encontrado por Ledo et al. (2002) em Bactris gasipaes Kunth, e Bezerra et al. (2002a), em Momordica charantia. Isto, deve-se, possivelmente, à grande capacidade de retenção de umidade desse substrato, que absorve até cinco vezes o próprio volume em água (Filgueira, 2000). A maior velocidade de germina- 

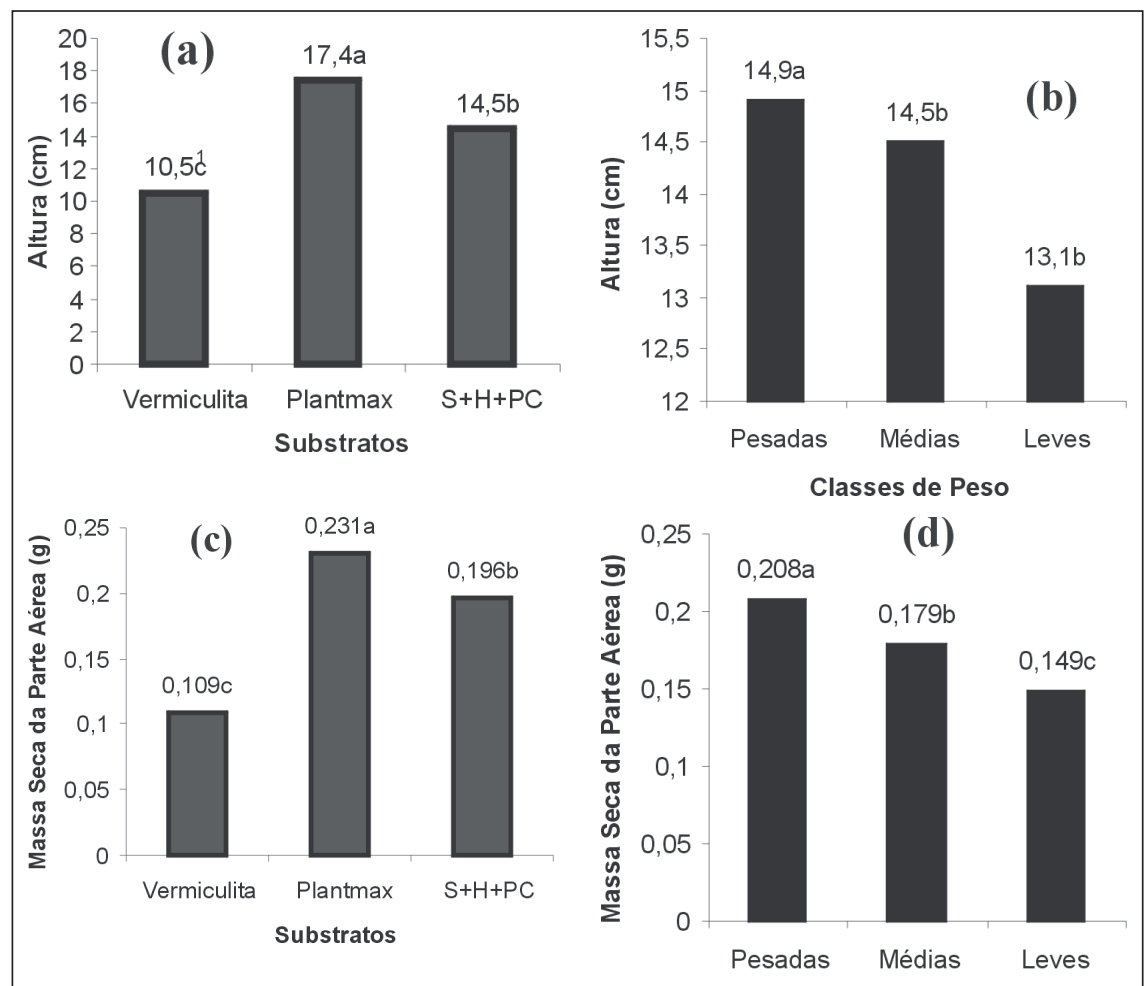

Classes de Peso
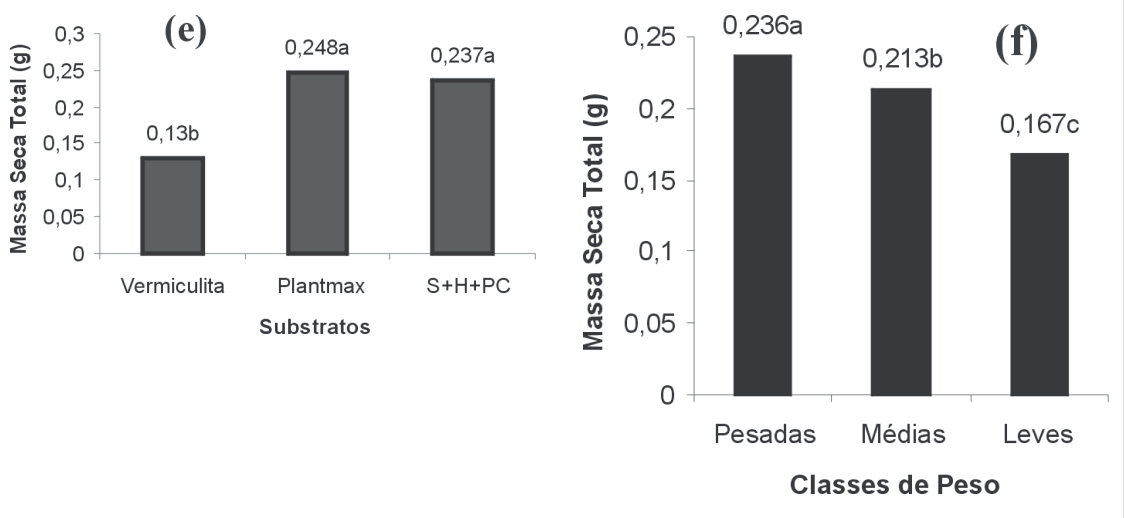

Figura 2. Altura (a e b), massas secas da parte aérea (c e d) e total (e e f) de plântulas de Moringa oleifera em função do peso da semente e do tipo de substrato. Fortaleza, UFC, 2003 ${ }^{1}$ Médias seguidas da mesma letra minúscula, no topo das colunas, não diferem entre si pelo teste de Tukey, em nível de 5,0\% de probabilidade.

ção no Plantmax ${ }^{\circledR}$ e na mistura $\mathrm{S}+\mathrm{H}+\mathrm{PC}$ assemelhou-se à detectada por Bezerra et al. (2002a), em Momordica charantia L., quando se utilizaram Plugmix ${ }^{\circledR}$ e solo como substratos.

Os índices de velocidade de germinação (Figura 1d) das sementes pesadas $(3,83)$ e médias $(3,85)$ foram similares mas diferiram estatisticamente das sementes leves (3,57). Martins et al. (2000) observaram que as sementes de Euterpe espirotosantensis de menor peso $(0,78 \mathrm{~g})$ apresentaram velocidade de germinação inferior às classes de sementes com peso superior a $0,97 \mathrm{~g}$.
A velocidade de germinação, medida pelo tempo médio (Figura 1e e 1f), revelou que o tempo necessário para que as sementes expressem a sua máxima capacidade de germinação foi de 5,99 e 6,18 dias nos substratos Plantmax ${ }^{\circledR}$ e $\mathrm{S}+\mathrm{H}+\mathrm{PC}$, enquanto nas sementes pesadas e nas médias, os valores do tempo médio situaram-se em torno de 6,35 e 6,31 dias, respectivamente. Esses resultados foram inferiores àqueles observados por Oliveira (2000), em sementes intactas de moringa, nas mesmas condições ambientais, tendo areia como substrato, cujo tempo médio situou-se em torno de 9,27 dias.

O substrato Plantmax ${ }^{\circledR}$ proporcionou condições mais adequadas ao crescimento das plântulas, haja vista o maior crescimento (Figura 2a) e produção de massa seca da parte aérea (Figura 2c) e total (Figura 2e) em relação aos outros dois. No Plantmax $\AA^{\circledR}$, substrato de melhor desempenho, cuja taxa de crescimento foi por volta de $1,2 \mathrm{~cm} \cdot \mathrm{dia}^{-1}$, o comportamento foi semelhante ao obtido por Oliveira (2000), na mesma espécie, em sementes pré-embebidas em água por $24 \mathrm{~h}$. A taxa de crescimento na vermiculita $\left(0,7 \mathrm{~cm} \cdot \mathrm{dia}^{-1}\right)$ foi idêntica à observada por Jahn (1989) em sacos de polietileno contendo a mistura solo preto, solo vermelho e esterco bovino curtido, na proporção de $1: 1: 1$, como substrato, e inferior a encontrada por Silva e Kerr (1999), na mesma espécie, sob condições de casa de vegetação (2 $\left.\mathrm{cm} \cdot \mathrm{dia}^{-1}\right)$. Vale salientar que a mistura composta de solo esterilizado, húmus de minhoca e pó de coco lavado apresentou um desempenho satisfatório no desenvolvimento das plântulas de moringa sendo somente suplantada pelo substrato Plantmax ${ }^{\circledR}$.

A separação das sementes em pesadas e leves influenciou diretamente a altura (Figura 2b) e a biomassa da parte aérea (Figura 2d) e total (Figura 2f), onde as pesadas foram mais vigorosas do que as leves. Bezerra et al. (2002b) também obtiveram resultados semelhantes quando trabalharam com sementes de copaíba. Carvalho e Nakagawa (2000) asseguram que, em uma mesma espécie, as sementes de maior peso, por serem mais bem nutridas durante o seu desenvolvimento, possuem embriões bem formados e com maior quantidade de reservas, sendo, por conseguinte, mais vigorosas, originando plântulas mais desenvolvidas. Os valores médios da altura (Figura 2b) e massa seca da parte aérea (Figura 2d) das plântulas revelam que as sementes de peso médio, exibiram comportamento semelhante às pesadas. Saliente-se, ainda, que as sementes médias tiveram um desempenho superior às leves no desenvolvimento das plântulas de moringa.

Diante do exposto verificou-se que o peso da semente favoreceu a germi- 
nação e o vigor das sementes de moringa; as sementes pesadas proporcionaram plântulas mais vigorosas; a vermiculita não é substrato ideal para semeadura de sementes de moringa já que as plântulas desenvolveram-se melhor no substrato Plantmax $\AA^{\circledR}$.

\section{AGRADECIMENTOS}

Os autores agradecem ao Prof. Renato Innecco e ao Dr. Sérgio Horta Mattos do Departamento de Fitotecnia da UFC, pelo fornecimento das sementes, e aos alunos de graduação: Francisco José C. Moreira, Fred Denilson B. da Silva e Társio Thiago L. Alves, pela colaboração na condução do trabalho.

\section{LITERATURA CITADA}

AMAYA, D.R.; KERR, W.E.; GODOI, H.T.; OLIVEIRA, A.L.; SILVA, F.R. Moringa: hortaliça arbórea rica em beta-caroteno. Horticultura Brasileira, Brasília, v.10, n.2, p.126, 1992.

BEZERRA, A.M.E.; ALCANFÔR, D.C.; MEDEIROS FILHO, S.; INNECCO, R. Germinação de sementes de moringa (Moringa oleifera Lam.). Ciência Agronômica, Fortaleza, v.28, n.1/ 2, p.64-69, 1997.

BEZERRA, A.M.E.; MOMENTÉ, V.G.; ARAÚJO, E.C.; MEDEIROS FILHO, S. Germinação e desenvolvimento de plântulas de melão-de-sãocaetano em diferentes ambientes e substratos. Revista Ciência Agronômica, Fortaleza, v.33, n.1, p 39-44, 2002a.

BEZERRA, A.M.E.; MEDEIROS FILHO, S.; MOREIRA, M.G.; MOREIRA, F.J.C.; ALVES, T.T.L. Germinação e desenvolvimento de plântulas de copaíba em função do tamanho e da imersão da semente em ácido sulfúrico. Revista Ciência Agronômica, Fortaleza, v.33, n.2, p. 79-84, 2002b. BRASIL. Ministério da Agricultura e Reforma Agrária. Regras para análise de sementes. Brasília: SNDA/DNDV/CLAV, 1992. $395 \mathrm{p}$ CÁCERES, A.; FREIRE, V.; GIRÓN, L.M.; AVILÉS, O.; PACHECO, G. Moringa oleifera (Moringaceae): etnobotanical studies in Guatemala. Economic Botany, v.45, n.4, p.522523, 1991.

CARRIJO, O.A.; LIZ, R.S.; MAKISHIMA, N. Fibra da casca do coco verde como substrato agrícola. Horticultura Brasileira, Brasília, v.20, n.4, p.533-535, 2002.
CARVALHO, N.M.; NAKAGAWA, J. Sementes: ciência, tecnologia e produção. 4.ed. Jaboticabal: FUNEP, 2000. 588 p.

FILGUEIRA, F.A.R. Novo manual de olericultura: agrotecnologia moderna na produção e comercialização de hortaliças. Viçosa: UFV, 2000. 402 p.

FERREIRA, P.V. Estatística experimental aplicada à agronomia. 2. ed. Maceió: EDUFAL, 1996. $604 \mathrm{p}$.

GASSENSCHMIDT, U.; JANY, K.D.; TAUSCHER, B.; NIEBERGALL, H. Isolation and characterization of a flocculating protein from Moringa oleifera Lam. Biochemistry Biophysical Acta, v.13, p.477-481, 1995.

GERDES, G. O uso das sementes da árvore moringa para o tratamento de água turva. ESPLAR - Centro de Pesquisa e Assessoria: Fortaleza, 13 p., 1996. (Boletim Técnico)

GERDES, G. Como limpar e tratar água suja com sementes da moringa. ESPLAR - Centro de Pesquisa e Assessoria, Fortaleza, 18 p., 1997. (Boletim Técnico)

GONÇALVES, A.L. Substratos para produção de mudas de plantas ornamentais. In: MINAMI, K (Org.) Produção de mudas de alta qualidade em horticultura. São Paulo: Queiroz, T.A., 1995, p.107-116.

JAHN, S.A.A. Proper use Moringa oleifera for food and water purification - Selection of clones and growing of annual short-stem. Pflanzenzucht, v.4, p.22-25, 1989.

KERR, W.E.; SILVA, F.R.; RESENDE, A.; GODOI, H.T.; KERR, L.S. Moringa oleifera: distribuição de sementes dessa hortaliça arbórea Horticultura Brasileira, Brasília, v.16, n.1, 1998. Trabalho apresentado no $38^{\circ}$ Congresso Brasileiro de Olericultura, 1998.

LABOURIAU, L.G. A germinação das sementes. Washington: OEA, 1983. $174 \mathrm{p}$.

LEDO, A.S.; MEDEIROS FILHO, S.; LEDO, F.J.S.; ARAÚJO, E.C. Efeito do tamanho da semente, do substrato e pré-embebição na germinação de sementes de pupunha. Revista Ciência Agronômica, Fortaleza, v.33, n.1, p.29-32, 2002. MAGUIRE, J.D. Speed of germination-aid in selection and evaluation for seedling emergence and vigor. Crop science, v.2, n.1, p.176-177, 1962. MAKKAR, H.P.S.; BECKER, K. Nutrients and antiquality factors in different morphological parts of the Moringa oleifera tree. Journal of Agricultural Science, Cambridge, v.128, p.331322, 1997.

MARTINS, C.C.; NAKAGAWA, J.; BOVI, M.L.A.; STANGUERLIM, H. Influência do peso das sementes de palmito-vermelho (Euterpe espirotosantensis Fernandes) na percentagem e na velocidade de germinação. Revista Brasileira de Sementes, Londrina, v.22, n.1, p.147-153, 2000.
MATOS, F.J. A. Farmácias Vivas: sistemas de utilização de plantas medicinais projetados para pequenas comunidades. 3.ed. Fortaleza: EUFC, 1998. 220 p.

MORTON, J. The horseradish tree, Moringa pterygosperma (Moringaceae) - a boon to arid lands?. Economy Botany, v.45, n.3, p.318-333. 1991.

NAKAGAWA, J. Testes de vigor baseados na avaliação das plântulas. In: VIEIRA, R.D.; CARVALHO, N.M. Testes de Vigor em Sementes. Jaboticabal: FUNEP, 1994. p.49-85.

O FILTRO natural: experiência com semente de moringa reduz endemias em águas contaminadas. Revista Abastece, v.1, n.2, p.22, 1999.

OLIVEIRA, J.T.A.; SILVEIRA, S.B.; VASCONCELOS, I.K.M.; CAVADA, B.S.; MOREIRA, R.A. Compositional and nutritional attributes of seeds from the multiple purpose tree Moringa oleifera Lamarck. Journal of the Science of Food and Agriculture, v.79, p.815-820, 1999.

OLIVEIRA, V.C. Germinação de sementes de moringa (Moringa oleifera Lam.). 2000. 29 p. (Monografia Graduação), UFC, Fortaleza.

PALADA, M.C. Moringa (Moringa oleifera Lam.): a versatile tree crop with horticultural potential in the Subtropical United States. HortScience, v.31, n.5, p.794-797, 1996

PIO CORRÊA, M. Dicionário das plantas úteis do Brasil e das exóticas cultivadas. Rio de Janeiro: MA/IBDF, v.5, p.233-234. 1984.

RAMACHANDRAN, C.; PETER, K.V.; GOPALAKRISHNAN, P.K. Drumstick (Moringa oleifera) a multipurpose Indian vegetyable. Economy Botany, v.34, p.276-283, 1980.

SILVEIRA, E.B.; RODRIGUES, V.J.L.B.; GOMES, A.M.A.; MARIANO, R.L.R.; MESQUITA, J.C.P. Pó de coco como substrato para produção de mudas de tomateiro. Horticultura Brasileira, Brasília, v.20, n.2, p.211-216, 2002.

SILVA, A.R.; KERR, W.E. Moringa: uma nova hortaliça para o Brasil. Uberlândia: UFU/DIRIU, 1999, 95 p.

WARHURST, A.M.; McCONNACHIE, G.L.; POLLARD, S.J.T. The production of activated carbon for water treatment in Malawi from the waste seed husks of Moringa oleifera. Water Science Technology, v.34, n.11, p.117-184, 1996. WARHURST, A.M.; McCONNACHIE, G.L.; POLLARD, S.J.T. Characterisation and applications of activated carbon produced from Moringa oleifera seed husks by single-step steam pyrolysis. Water Research, v.31, n.4, p.759-766, 1997. 